\title{
Spinal Meningiomas: A Review
}

\section{Michael A Galgano, Timothy Beutler, Aaron Brooking and Eric M Deshaies*}

Department of Neurosurgery, SUNY Upstate Medical University, Syracuse, NY, USA

\begin{abstract}
Meningiomas of the spinal axis have been identified from $\mathrm{C} 1$ to as distal as the sacrum. Their clinical presentation varies greatly based on their location. Meningiomas situated in the atlanto-axial region may present similarly to some meningiomas of the craniocervical junction, while some of the more distal spinal axis meningiomas are discovered as a result of chronic back pain. Surgical resection remains the mainstay of treatment, although advancements in radiosurgery have led to increased utilization as a primary or adjuvant therapy. Angiography also plays a critical role in surgical planning and may be utilized for preoperative embolization of hypervascular meningiomas.
\end{abstract}

Keywords: Meningioma; Neurosurgery; Radiosurgery; Angiography

\section{Introduction}

Spinal meningiomas are tumors originating from arachnoid cap cells most commonly situated in the intradural extramedullary region $[1,2]$. They represent a high proportion of all spinal cord tumors. Spinal meningiomas tend to predominate in the thoracic region, although they are described in the cervical, lumbar, and rarely the sacral area [3-5]. They pose varying surgical challenges based on their regional location, as well as their anterior/posterior orientation to the spinal cord and cauda equina. We will discuss the various locations of spinal axis meningiomas, as well as the different surgical approaches, and adjuvant therapies.

\section{Spinal Meningiomas}

\section{Epidemiology}

Intradural extramedullary spinal cord tumors account for approximately two-thirds of all spinal cord tumors in adults [6]. Meningiomas, neurofibromas, and schwannomas are the most common type of tumor in this type of location [7,8]. Meningiomas represent about $40 \%$ of these tumors [6].

The vast majority of spinal cord meningiomas are located in the thoracic region (Figure 1) [3-5,9]. This predominance of thoraciclocated meningiomas is seen only in females [10]. Spinal meningiomas occur about 2.5 times more often in females than males; with approximately $75-85 \%$ arising in women. The female preponderance is thought to arise from sex hormones or other receptor types common to women [10]. Some authors believe that progesterone and estrogen receptors actually have opposing prognostic indications in regards to meningiomas. Pravdenkova et al. observed that the expression of progesterone receptors alone in meningiomas, signifies a more

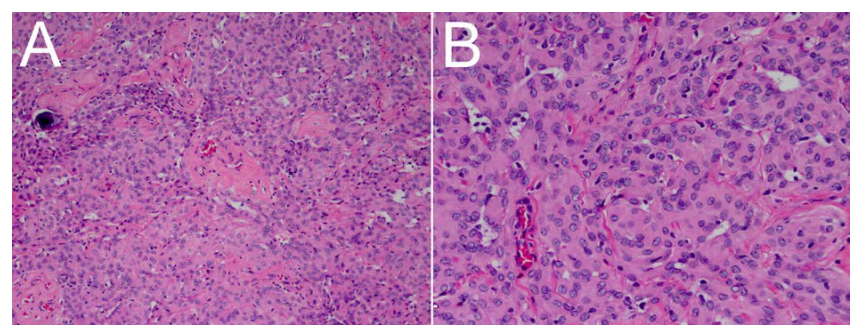

Figure 1: 10X (A) and 20X (B) magnification. Hematoxylin and eosin stain shows monotonous cells with bland histology and poorly defined cell borders. Inconspicuous nucleoli are seen. The cells have round to oval nuclei and rare nuclear pseudoinclusions. Mitotic figures are not present. Whorls and a single calcification (Psammoma body) are present. favorable and biological outcome [11]. They also found that either a lack of estrogen and progesterone receptors, or the presence of estrogen receptors in meningiomas, correlated with a more aggressive clinical behavior, progression, and recurrence. Hsu and Hedley Whyte also found that the presence of progesterone receptors, even in a small subgroup of tumor cells, indicated a more favorable prognostic value for meningiomas [12].

An interesting epidemiological feature of spinal meningiomas, is that not only are they more common in women, but there is a sharp rise in postmenopausal females [9]. It has been postulated that these tumors are so grossly over-represented in postmenopausal females as a result of an association with osteoporosis. Previous authors have made suppositions that meningeal stretching or spinal meningeal trauma from direct contact with bone fragments of osteoporotic fractures, may in fact lead to a meningeal reparative proliferative process leading to tumor formation [9].

Meningiomas may also be found in the region of the atlas and axis. The incidence of cervical meningiomas is about $14-27 \%$ [10]. They have a similar clinical presentation as foramen magnum meningiomas. The reason for this is that many cervicomedullary junction meningiomas expand to the high cervical region, just as many high cervical meningiomas expand rostrally through the foramen magnum [6]. Surgical treatment of meningiomas located in the high cervical region must be done with care to minimize bony removal in order to maintain mechanical stability [6]. The majority of spinal meningiomas are intradural, however a small percentage can be extradural, or both intradural and extradural. Although extremely rare, intradural, intramedullary spinal meningiomas have been described [13-16]. The incidence of lumbar spinal meningiomas is about $2-14 \%$ [10]. Sacral meningiomas have been described, although extremely rare [17].

Overall, spinal meningiomas account for about $7.5-12.7 \%$ of all meningiomas, occurring with less frequency than their intracranial

${ }^{*}$ Corresponding author: Eric M. Deshaies, MD, Director, SUNY Upstate Neurovascular Institute; Director, Cerebrovascular, Endovascular, and Skull Base Neurosurgery; Surgical Director, Neurocritical Care Unit, Director, Endovascular Fellowship Program, Associate Professor of Neurosurgery, Neuroscience \& Physiology, SUNY Upstate Medical University, 750 East Adams Street Syracuse, NY 13210, USA, Tel: 315-464-5502; Fax: 315-464-6373; E-mail: deshaiee@upstate.edu

Received December 06, 2013; Accepted February 03, 2014; Published February 06, 2014

Citation: Galgano MA, Beutler T, Brooking A, Deshaies EM (2014) Spinal Meningiomas: A Review. J Spine 3: 157. doi:10.4172/2165-7939.1000157

Copyright: (c) 2014 Galgano MA, et al. This is an open-access article distributed under the terms of the Creative Commons Attribution License, which permits unrestricted use, distribution, and reproduction in any medium, provided the original author and source are credited. 


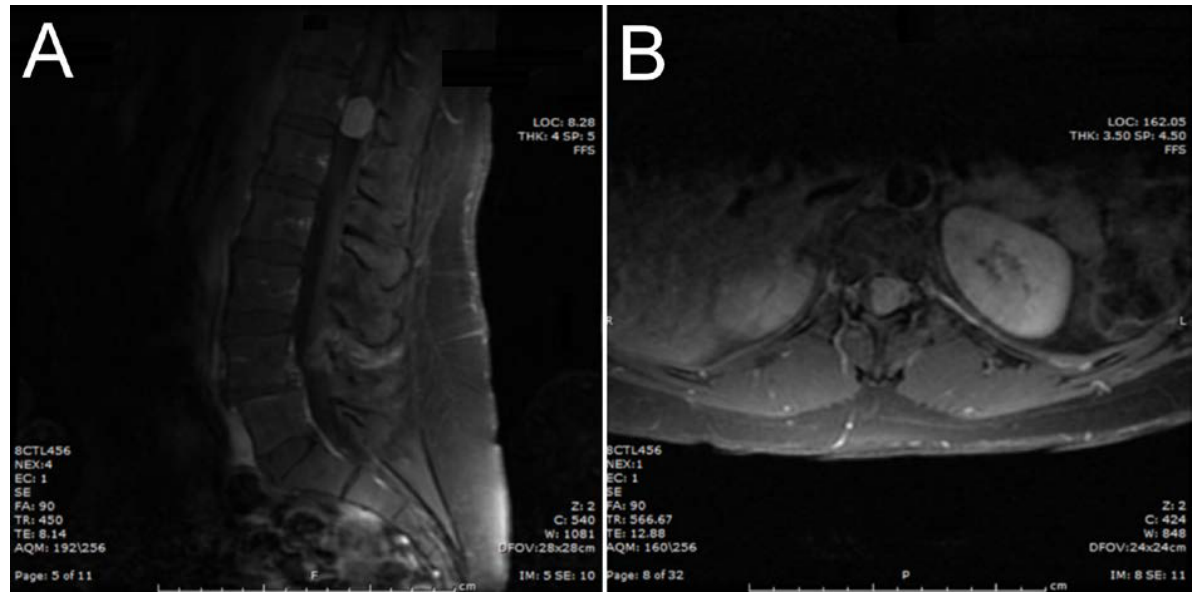

Figure 2: Sagital (A) and Axial (B) views of a T1 weighted MRI with contrast, showing an intradural extramedullary meningioma causing mass effect on the lower thoracic spinal cord.

counterpart. Most spinal cord meningiomas are located laterally. They typically arise from arachnoid cap cells embedded in the dural root sleeve [6]. They can also arise from pial or dural fibroblasts. This may be accounted for by their mesodermal origin [18].

\section{Diagnosis}

MRI is the imaging modality of choice since it often delineates the characteristic dural origin of meningiomas. They are typically isointense or hypointense to gray matter on $\mathrm{T} 1$, and isointense or hyperintense on T2. Intraspinal meningiomas radiographically display avid homogenous enhancement with contrast (Figure 2) [19]. Enhancement of the adjacent dura, or dural tail, is also characteristic of a meningioma [20]. CT scan will often demonstrate a calcified lesion in the spinal canal [19]. Radiographic evidence of a calcified spinal meningioma on plain $\mathrm{x}$-rays is exceedingly rare, but some reports have quoted such a finding [21].

The dural attachment of spinal meningiomas is typically quite broad. En plaque types of meningiomas are rare. However, partial circumferential calcification of the dura should raise the suspicion of this uncommon subtype of meningioma [22]. More commonly, spinal meningiomas are grossly smooth and fibrous, or fleshy with friable features [23]. There is usually a very well-defined epidural space in the spine. This is likely the main reason bony involvement is so rare in spinal meningiomas, as opposed to intracranial meningiomas. Also, unlike their intracranial counterparts, spinal meningiomas do not penetrate the pia. One reason this may be the case is that the manifestation of spinal cord compression and myelopathy are typically noticed by the patient "earlier" than the average intracranial meningioma. Therefore, surgical resection may be undertaken before penetration of the pial layer occurs [24]. This particular trait of pial preservation is also postulated in part by what has been described as an "intermediate leptomeningeal layer" [24]. This works in favor of a more complete and simplified surgical resection.

\section{Associations with neurofibromatosis Type 2 (NF2)}

The neurofibromin 2 gene (NF2) is located at the 12.2 region on chromosome 22. Loss of heterozygosity of the NF2 gene is the most common genetic abnormality found in meningiomas, and is responsible for $60 \%$ of sporadic as well as the majority of NF2 associated meningiomas. The NF2 gene codes for the protein Merlin. The function of Merlin is not well understood, however, it is thought to play a role in the 2 hit model of tumor inactivation. Up to $60 \%$ of meningiomas have an associated NF2 gene mutation, which may serve as the initiating event of tumorigenesis, particularly those demonstrating a mesenchymal phenotype [25].

\section{Clinical presentation}

Clinically, intraspinal meningiomas may have varying presentations depending on where they are located along the spinal axis. Craniocervical junction and high cervical junction meningiomas typically present with some degree of myelopathic features and suboccipital pain. They may also cause atrophy of intrinsic hand muscles. Spinal tumors in general may cause a dull ache, and may also cause radicular symptoms if a nerve root is involved [25]. Hydrocephalus is a rare sequelae of spinal meningiomas at any level, but is most common with meningiomas in the cervical region [26]. This is likely from increased protein production by the tumor, causing obstruction of CSF flow and absorption [26]. Corticospinal tracts are particularly vulnerable with thoracic tumors such as meningiomas. A clinical picture of thoracic myelopathy may ensue, displaying as long-tract signs. A foot drop may be an initial finding, with weakness of the tibialis anterior and extensor hallucis longus. Dorsally located midline thoracic meningiomas may cause a sensory ataxia from mass effect upon the posterior columns [6]. Bowel and bladder involvement may be a late manifestation. A common complaint of patients with extramedullary meningiomas is pain with recumbancy [6].

\section{Resection}

Traditionally, a posterior or posterolateral approach has been employed for cervical meningiomas, whether they are predominantly located dorsally, laterally, or even ventrally. Cervical meningiomas often can be a surgical challenge, as they are more often situated anterior to the spinal cord, as opposed to thoracic meningiomas which have a predilection for more posterior and lateral locations [27]. Klekamp and Samii reported on 130 spinal meningiomas, $27 \%$ of which were located in an anterior location [23]. These were all resected via a posterior approach including a laminectomy with or without facet joint resection. No specific indications for cervical-based meningiomas was given in this series [23]. Solero et al. reported on 174 spinal meningiomas and used a posterior approach for all posterior cervical meningiomas and all 7 of the reported anterior situated meningiomas [5]. In the majority of intraspinal meningiomas including those situated in the ventral cervical region, a posterior laminectomy gives adequate exposure [6]. 
Large ventrally located tumors may retract the spinal cord to some degree, and as a result, can still be approached posteriorly. To augment further anterior exposure through a posterior approach, subtle surgical maneuvers may be employed. Suturing of a noncritical dural root or a divided dentate ligament may be used as further retraction [6]. However, the posterior cervical approach still carries some degree of spinal cord manipulation to reach a ventrally-located meningioma. This may place the patient at higher risk of cord injury during the surgery. Dorsally-located cervical meningiomas can be approached via standard posterior cervical exposure. Although this is the approach of choice it may require stabilization if the patient becomes kyphotic over time [28].

The anterior cervical approach has also been used with success in resecting ventral cervical meningiomas [27,29-32]. Advantages of an anterior approach to ventral cervical meningiomas include a large bony window for surgical exposure with direct visualization of the intradural pathology ventral to the spinal cord, extradural coagulation of anterior tumor feeders, and lack of necessity for cervical cord manipulation and retraction [27]. Lenelle et al. described an anterior cervical meningioma behind the $\mathrm{C} 5$ vertebral body that was resected with good neurological outcome, via a C5 corpectomy, while also taking the lower part of C4 and the upper part of C5 [32]. Sawa et al. reported a meningioma from the foramen magnum down to T2 [31]. This tumor was fully resected via a C3-T1 corpectomy also with a good neurological outcome. Banczerowski et al. described an anterior resection of $\mathrm{C} 3$ and $\mathrm{C} 5$ meningioma via corpectomies at those respective levels [29]. A significant disadvantage of the anterior cervical approach includes the necessity for a minimum of anterior cervical fixation. In cases of a three-level corpectomy, supplementary posterior fixation has been shown to increase biomechanical stability [33]. An additional disadvantage of an anterior approach is the potential for a CSF leak. Although this is certainly a risk with a posterior approach as well, with anterior approaches, there tends to be a fair amount of dead space between the dura and bone graft or cage [27]. In light of an anterior CSF leak, there is minimal to no tamponade effect due to this previously described dead space, and this can lead to post-operative complications related to the leak. This may be prevented by a watertight dural closure, application of fibrin glue, prophylactic lumbar drain, and filling the dead space with muscle fascia from a site such as the iliac crest $[29,34,35]$.

Ventrally located cervical meningiomas with an eccentric component may be accessed via a hemilaminectomy and facetectomy. Ventral thoracic tumors may also be accessed via a costotransversectomy or lateral extracavitary approach [36]. Anterior transthoracic approaches are can be used for extradural thoracic lesions. This surgical technique is less frequently used for their intradural counterparts such as meningiomas. However, a transthoracic transvertebral approach has been described before for an anterior thoracic intradural calcified meningioma [37].

On rare occasion, a spinal meningioma may present as a dumbbell tumor, which has the appearance of a nerve sheath tumor. In order to resect this type of tumor, the nerve root at the level affected is typically sacrificed with minimal neurological sequelae $[6,38]$. The exceedingly rare intramedullary meningioma has been treated using surgical cordectomy as the operative technique [39]. Although uncommon, meningiomas have been described in the lumbosacral spine [17,40-43].

Overall, spinal meningiomas have some favorable features relative to intracranial meningiomas in regards to their resection. Typically, there is no bony involvement and major blood vessels are not usually in the path of surgical resection [24,44]. In regards to the dural base of the meningioma, a surgeon may opt to coagulate the dura extensively, or may excise the involved dural component, with subsequent patch graft reconstruction. No significant differences in recurrence rates have been found with these two techniques [5]. Long-term recurrence rates after total resection range between 3 and $23 \%[4,18,38,45]$.

Multiple spinal meningiomas are a relatively rare occurrence, especially outside the association with NF2 [46,47]. Treatment options for multiple spinal meningiomas must be tailored to their locations and the symptoms they are causing, as well as the premorbid condition of the patient. Meningiomas causing significant myelopathic or radiculopathic features should be treated, as opposed to watchful waiting. Surgery should be the mainstay of treatment for symptomatic multiple spinal meningiomas, although radiation treatment may play a role as well [48].

\section{Radiation Therapy}

The use of radiosurgery and adjunctive radiation therapy for the treatment of craniovertebral and spinal meningiomas is an evolving topic. Microdissection and resection of spinal meningiomas remains the gold standard for treatment [18,49-52]. Adjunctive radiation therapy is considered primarily in cases of subtotal resection of recurrent meningiomas and/or when the risk of surgery is too high given the patient's comorbidities or tumor location [49]. Frequently cited reasons for subtotal resection of meningiomas include an anterior tumor location (particularly in the thoracic area), recurrent tumors with arachnoid scarring and cord tethering, and en plaque and calcified meningiomas $[18,49-51,53]$.

Because of the well documented success of primarily treating intracranial meningiomas with radiosurgery, it has been thought that radiation would be successful in spinal tumors of similar pathology [51]. However, historically, primary radiosurgery treatment of spinal lesions has been problematic because conventional external beam radiotherapy relied on manual patient positioning and lacked the precision to deliver a large enough dose safely near the spinal cord $[51,54]$. Unlike intracranial systems that utilize the cranium as a rigidly immobilized reference to the lesion, early spinal systems used an invasive external frame system that was attached directly to the spine $[51,52,54]$. Subsequently, several frameless stereotactic radiosurgery techniques have been developed which utilize real time image tracking to achieve spatial accuracy of $1 \mathrm{~mm}$ [51-54]. These systems allow high dose fractions of radiation to be delivered to the target tissue while sparing adjacent structures [51,54]. For conventional fractionated external beam therapy the dose tolerance for the spinal cord is thought to be 45 to 50 Gy delivered in 1.8 to 2 Gy fractions [50,52]. Proton stereotactic radiosurgery has also been reported with similar promising results with the advantage of delivering significantly lower radiation to normal tissue [55].

Recent results of radiosurgery for spinal meningioma treatment have been promising. The response rates seen with radiosurgery for spinal meningiomas appear to be comparable to responses rates for similar intracranial lesions [53]. While most studies lack adequate long term follow-up necessary to establish the durability of the procedure, the majority of patients have been found to have stable or decreased tumor size on subsequent radiographic imaging [50]. In a study on foramen magnum meningiomas, Zenonos et al. found that 10 of 17 patients had symptomatic improvement with the remaining 7 patients remaining clinically stable at 6 months. Dodd et al. showed in a study of 51 patients with benign intradural spinal lesions, that at one year follow-up, $61 \%$ of the patients had stable lesions and $39 \%$ had 
smaller lesions, with only 3 patients requiring surgery for worsening symptoms [50]. Gerszten et al. showed in a series of papers good long term radiographic control and symptomatic improvement for patients treated with both primary and adjunctive radiosurgery [51,54]. Other authors have reported similar results [50,53]. The technique seems to be effective in reversing neurologic deficits due to radiculopathies with better improvement for symptoms of pain and strength rather than sensory loss $[50,56]$. Small asymptomatic tumors were more likely to have excellent regression responses and small symptomatic tumors were more likely to have symptomatic improvement [57]. Large tumors with significant brain stem compression and severe disability were not found to benefit from radiosurgery [57].

One of the major complications of radiation therapy is radiation induced myelopathy [50]. Delayed myelopathy has been of particular concern for radiosurgery of benign spinal lesions such as meningiomas. This concern stems from the fact that patient populations with these pathologically benign lesions have prolonged life expectancies compared to those with malignant lesions, and thus, myelopathy can be a burdensome side-effect to deal with on a chronic basis [51]. The reported incidence of radiation complications ranges from 0.2 to $5 \%$ [54]. Factors that have been associated with this complication include total dose and fraction size, length of irradiated spinal cord, and the duration of treatment $[50,52]$. Some authors have hypothesized that previous open surgery may predispose the spinal cord to subsequent radiation injury and have observed that the lower cervical levels and dorsal columns appear to be more susceptible [53]. Two types of radiation injury can occur. The first type is spinal cord edema, which may resolve spontaneously after completion of therapy, while the second is delayed myelopathy [54]. Delayed myelopthy typically occurs between 6 and 24 months [50,52]. Diagnosis of cord damage can be seen on T2-weighted signal changes and have been reported to be treated with a combination of steroids, vitamin $\mathrm{E}$ and gabapentin [52].

Overall, radiation therapy for selected spinal meningiomas, is a plausible treatment option in the repertoire of the neurosurgeon.

\section{Angiography}

Spinal angiography is often performed prior to surgical intervention in the case of lower thoracic meningiomas [58]. The artery of Adamkiewicz is the major provider of blood supply to the lumbar and sacral spinal cord. This is the largest known anterior segmental medullary artery. This artery is typically located between T8 and L3, and at $\mathrm{T} 9$ or $\mathrm{T} 10$ in about $50 \%$ of cases. It originates from the left side roughly $75 \%$ of the time [59]. Unintentional interruption to this vessel during surgery could result in ischemia of the ventral horn of the spinal cord, in addition to the ventral commissura and the sympathetic centers of the intermediolateral region. This can subsequently manifest as distal paraplegia, pain and temperature sensory loss, and incontinence of bowel and bladder functions. Pre-operative spinal angiography allows safe determination of the topography of the artery of Adamkiewicz. If a spinal meningioma is located at the same level as this artery, a contralateral surgical approach, or other selective surgical technique may be employed to avoid damaging this important vessel [59].

Spinal angiography can also be used pre-operatively as a means of embolization. Some spinal meningiomas are hypervascular, and resection of such lesions can become hazardous or may incite termination of the procedure due to excessive intra-operative hemorrhage [60]. The goal of this pre-surgical maneuver is to decrease the vascularity of the tumor, by embolizing artery-to-artery deep capillary tumor bed feeders [61]. Pre-operative spinal meningioma embolization has the ability to facilitate surgical resection by reduction of intraoperative hemorrhage, shrinking the tumor, and giving the surgeon an unimpeded surgical field. These benefits can augment a more complete tumor resection.

\section{Conclusion}

Spinal cord meningiomas represent a relatively high proportion of spinal cord tumors. Their location is most typically in the thoracic and cervical regions, however the less common lumbar and sacral meningiomas are described. Posterior or posterolateral approaches are most commonly employed for both ventral and dorsal spinal meningiomas, although anterior cervical and anterior transthoracic approaches are warranted for specific situations. Adjuvant radiation treatment for spinal meningiomas is becoming an important treatment modality in cases where there is incomplete surgical resection. When hypervascular meningiomas are suspected based on standard imaging and angiography, pre-operative embolization can be utilized to aid the surgeon with a safer resection.

\section{Acknowledgement}

We thank Dr. Joseph M. Fullmer and the Neuropathology Department for their assistance with the histology.

\section{References}

1. Mawrin C, Perry A (2010) Pathological classification and molecular genetics of meningiomas. J Neurooncol 99: 379-391.

2. McLendon RE, Rosenblum MK, Bigner DD (2006) Russell and Rubinstein's Pathology of Tumors of the Nervous System. CRC Press.

3. Roux FX, Nataf F, Pinaudeau M, Borne G, Devaux B, et al. (1996) Intraspinal meningiomas: review of 54 cases with discussion of poor prognosis factors and modern therapeutic management. Surg Neurol 46: 458-463.

4. Levy WJ Jr, Bay J, Dohn D (1982) Spinal cord meningioma. J Neurosurg 57 804-812.

5. Solero CL, Fornari M, Giombini S, Lasio G, Oliveri G, et al. (1989) Spinal meningiomas: review of 174 operated cases. Neurosurgery 25: 153-160.

6. Winn HR (2011) Youmans Neurological Surgery. Elsevier Health Sciences

7. Bucci MN, McGillicuddy JE, Taren JA, Hoff JT (1990) Management of anteriorly located C1-C2 neurofibromata. Surg Neurol 33: 15-18.

8. Hu HP, Huang QL (1992) Signal intensity correlation of MRI with pathological findings in spinal neurinomas. Neuroradiology 34: 98-102.

9. Preston-Martin S, Monroe K, Lee PJ, Bernstein L, Kelsey J, et al. (1995) Spina meningiomas in women in Los Angeles County: investigation of an etiological hypothesis. Cancer Epidemiol Biomarkers Prev 4: 333-339.

10. Lee JH (2008) Meningiomas: Diagnosis, Treatment, and Outcome. Springer.

11. Pravdenkova S, Al-Mefty O, Sawyer J, Husain M (2006) Progesterone and estrogen receptors: opposing prognostic indicators in meningiomas. J Neurosurg 105: 163-173.

12. Hsu DW, Efird JT, Hedley-Whyte ET (1997) Progesterone and estrogen receptors in meningiomas: prognostic considerations. J Neurosurg 86: 113 120.

13. Hafiz MG, Rahman MR, Yeamin MB (2013) Intradural intramedullary spinal cord meningioma in a seven years old female child. Mymensingh Med $\mathrm{J} 22$ : 180-185.

14. Moriuchi S, Nakagawa H, Yamada M, Kadota T (1996) Intramedullary spinal cord meningioma--a case report. Neurol Med Chir (Tokyo) 36: 888-892.

15. Sahni D, Harrop JS, Kalfas IH, Vaccaro AR, Weingarten D (2008) Exophytic intramedullary meningioma of the cervical spinal cord. J Clin Neurosci 15 1176-1179.

16. Yuan D, Liu D, Yuan XR, Xi J, Ding XP (2013) Intramedullary thoracic spinal cord meningioma: a rare case report and review of the literature. J Neurol Surg A Cent Eur Neurosurg 74 Suppl 1: e136-139.

17. Teo M, Zrinzo L, King A, Aspoas AR, David KM (2010) Giant extradural sacral meningioma. Acta Neurochir (Wien) 152: 485-488.

18. Gezen F, Kahraman S, Canakci Z, Bedük A (2000) Review of 36 cases of spinal cord meningioma. Spine (Phila Pa 1976) 25: 727-731. 
19. Weber DC, Lovblad KO, Rogers L (2010) New pathology classification, imagery techniques and prospective trials for meningiomas: the future looks bright. Curr Opin Neurol 23: 563-570.

20. Quekel LG, Versteege CW (1995) The "dural tail sign" in MRI of spinal meningiomas. J Comput Assist Tomogr 19: 890-892.

21. Doita M, Harada T, Nishida K, Marui T, Kurosaka M, et al. (2001) Recurrent calcified spinal meningioma detected by plain radiograph. Spine (Phila Pa 1976) 26: E249-252.

22. Gamache FW Jr, Wang JC, Deck M, Heise C (2001) Unusual appearance of an en plaque meningioma of the cervical spinal canal. A case report and literature review. Spine (Phila Pa 1976) 26: E87-89

23. Klekamp J, Samii M (1999) Surgical results for spinal meningiomas. Surg Neurol 52: 552-562.

24. Salpietro FM, Alafaci C, Lucerna S, lacopino DG, Tomasello F (1997) Do spinal meningiomas penetrate the pial layer? Correlation between magnetic resonance imaging and microsurgical findings and intracranial tumor interfaces. Neurosurgery 41: 254-257.

25. Stein BM, Leeds NE, Taveras JM, Pool JL (1963) Meningiomas of the Foramen Magnum. J Neurosurg 20: 740-751.

26. Feldmann E, Bromfield E, Navia B, Pasternak GW, Posner JB (1986) Hydrocephalic dementia and spinal cord tumor. Report of a case and review of the literature. Arch Neurol 43: 714-718.

27. Payer M (2005) The anterior approach to anterior cervical meningiomas: review illustrated by a case. Acta Neurochir (Wien) 147: 555-560.

28. Mayer M, Meier O, Auffarth A, Koller H (2013) Cervical laminectomy and instrumented lateral mass fusion: techniques, pearls and pitfalls. Eur Spine J.

29. Banczerowski P, Lipóth L, Vajda J, Veres R (2003) Surgery of ventral intradural midline cervical spinal pathologies via anterior cervical approach: our experience. Ideggyogy Sz 56: 115-118.

30. Giroux JC, Nohra C (1978) Anterior approach for removal of a cervical intradural tumor: case report and technical note. Neurosurgery 2: 128-130.

31. Sawa H, Tamaki N, Kurata H, Nagashima T (1993) Complete resection of a spinal meningioma extending from the foramen magnum to the second thoracic vertebral body via the anterior approach: case report. Neurosurgery 33: 10951098.

32. Lenelle J, Born JD, Collignon J (1986) [Ablation by the anterior transcorporeal approach of an ante-spinal cord cervical meningioma. Apropos of a case]. Neurochirurgie 32: 262-265

33. Singh K, Vaccaro AR, Kim J, Lorenz EP, Lim TH, et al. (2003) Biomechanical comparison of cervical spine reconstructive techniques after a multileve corpectomy of the cervical spine. Spine (Phila Pa 1976) 28: 2352-2358.

34. ljiri K, Hida K, Yano S, Iwasaki Y (2009) Ventrally located cervical intramedullary cavernous angioma: selection of posterior and anterior approaches: case report. Neurol Med Chir (Tokyo) 49: 474-477.

35. O'Toole JE, McCormick PC (2003) Midline ventral intradural schwannoma of the cervical spinal cord resected via anterior corpectomy with reconstruction: technical case report and review of the literature. Neurosurgery 52: 1482-1485

36. Steck JC, Dietze DD, Fessler RG (1994) Posterolateral approach to intradural extramedullary thoracic tumors. J Neurosurg 81: 202-205.

37. Jenny B, Rilliet B, May D, Pizzolato GP (2002) [Transthoracic transvertebra approach for resection of an anteriorly located, calcified meningioma. Case report]. Neurochirurgie 48: 49-52.

38. Kim MS, Eun JP, Park JS (2011) A dumbbell-shaped meningioma mimicking a schwannoma in the thoracic spine. J Korean Neurosurg Soc 50: 264-267.

39. Raza SM, Anderson WS, Eberhart CG, Wolinsky JP, Gokaslan ZL (2005) The application of surgical cordectomy in the management of an intramedullaryextramedullary atypical meningioma: case report and literature review. J Spinal Disord Tech 18: 449-454

40. Rutherford SA, Linton KM, Durnian JM, Cowie RA (2006) Epidural meningioma of the sacral canal. Case report. J Neurosurg Spine 4: 71-74.

41. Lista-Martínez O, Santín-Amo JM, Facal-Varela S, Rossi-Mautone E, RivasLópez LA, et al. (2012) [Multifocal clear cell meningioma in the sacral and lumbar spine. Case report and literature review]. Neurocir Astur 23: 259-263.
42. Bhadra AK, Casey AT, Saifuddin A, Briggs TW (2007) Primary atypical sacra meningioma--not always benign. Skeletal Radiol 36 Suppl 1: S91-94.

43. Tolias CM, Beale DJ, Sakas DE (1997) Giant lumbar meningioma: a common tumour in an unusual location. Neuroradiology 39: 276-277.

44. McCormick PC (1994) Anatomic principles of intradural spinal surgery. Clin Neurosurg 41: 204-223.

45. Guidetti B, Spallone A (1988) Benign extramedullary tumors of the foramen magnum. Adv Tech Stand Neurosurg 16: 83-120.

46. Petit $H$, Jomin M, Jeulin-Gaillard B, Warot P (1980) [Multiple "non-associated" spinal meningiomas]. Lille Med 25: 346-349.

47. Tsuji N, Nishiura I, Koyama T (1986) Extradural multiple spinal meningioma. Literature review a case report. Neurochirurgia (Stuttg) 29: 124-127.

48. Lloyd SK, Evans DG (2013) Neurofibromatosis type 2 (NF2): diagnosis and management. Handb Clin Neurol 115: 957-967.

49. Gottfried ON, Gluf W, Quinones-Hinojosa A, Kan P, Schmidt MH (2003) Spinal meningiomas: surgical management and outcome. Neurosurg Focus 14: e2.

50. Dodd RL, Ryu MR, Kamnerdsupaphon P, Gibbs IC, Chang SD Jr, et al. (2006) CyberKnife radiosurgery for benign intradural extramedullary spinal tumors. Neurosurgery 58: 674-685.

51. Gerszten PC, Ozhasoglu C, Burton SA, Vogel WJ, Atkins BA et al. (2003) CyberKnife frameless single-fraction stereotactic radiosurgery for benign tumors of the spine. Neurosurg Focus 2003 14: e16.

52. Gerszten PC, Burton SA, Ozhasoglu C, McCue KJ, Quinn AE (2008) Radiosurgery for benign intradural spinal tumors. Neurosurgery 62: 887-895

53. Kufeld M, Wowra B, Muacevic A, Zausinger S, Tonn JC (2012) Radiosurgery of spinal meningiomas and schwannomas. Technol Cancer Res Treat 11: 27-34.

54. Ryu SI, Chang SD, Kim DH, Murphy MJ, Le QT, et al. (2001) Image-guided hypo-fractionated stereotactic radiosurgery to spinal lesions. Neurosurgery 49 : 838-846.

55. Halasz LM, Bussière MR, Dennis ER, Niemierko A, Chapman PH, et al. (2011) Proton stereotactic radiosurgery for the treatment of benign meningiomas. Int $J$ Radiat Oncol Biol Phys 81: 1428-1435.

56. Hsu W, Nguyen T, Kleinberg L, Ford EC, Rigamonti D, et al. (2010) Stereotactic radiosurgery for spine tumors: review of current literature. Stereotact Funct Neurosurg 88: 315-321.

57. Samii PD med M, M.d MA (1992) Meningiomas Involving the Lower Clivus and the Foramen Magnum (Craniospinal Meningiomas) [Internet]; in : Surgery of Skull Base Meningiomas. Springer Berlin Heidelberg.

58. http://emedicine.medscape.com/article/341870-overview

59. Charles YP, Barbe B, Beaujeux R, Boujan F, Steib JP (2011) Relevance of the anatomical location of the Adamkiewicz artery in spine surgery. Surg Radio Anat 33: 3-9.

60. Shi HB, Suh DC, Lee HK, Lim SM, Kim DH, et al. (1999) Preoperative transarterial embolization of spinal tumor: embolization techniques and results. AJNR Am J Neuroradiol 20: 2009-2015

61. Gore P, Theodore N, Brasiliense L, Kim LJ, Garrett M, et al. (2008) The utility of onyx for preoperative embolization of cranial and spinal tumors. Neurosurgery 62: 1204-1211. 